\title{
Research of Women Dresses in the Tang Dynasty and the Modern Dresses Under the Perspective of Postmodernism
}

\author{
Qionghua Deng \\ Jiangxi Institute of Fashion Technology, Department of Dress Design and Engineering \\ Jiangxi Institute of Fashion Technology, JF \\ Nanchang, Jiangxi \\ E-mail: 348908682@qq.com
}

\begin{abstract}
Keywords: The Perspective of Postmodernism; The Women Dresses in the Tang Dynasty; Costume Culture; The Modern Dress;The Difference
\end{abstract}

\begin{abstract}
The culture of the Tang Dynasty had the characters of diversification and secularization, especially the women dress aesthetic culture had become the unique culture in the costume history of China. The modern women dress has the inheritance relationship with the women dress in the Tang dynasty. The modern women dress not only has the aesthetic characters with lush and exotic, but also times fragrance with the melting of elegance and sparkling. The modern women dress has the characters of diversification and secularization under the perspective postmodernism, which has the internal relation that could not be split with the Tang dynasty women dress in the spirit. From the aspect, we could say that the modern women dress has the inheritance relationship with the women dress in the Tang dynasty. Through the research of the two dresses, we could make use of the traditional costumes culture in the development of modern dress.

In the Tang Dynasty, the economy was prosperous and thriving; the military force was strong; the culture and the art were booming. The clothes in the Tang Dynasty had all the advantages of home and abroad. Therefore, the unique culture in the Tang Dynasty was formed under this background. The women dressing in the Tang Dynasty absorbed the advantages of foreign countries in the facade, and also melt elegant demeanor of our minority nationalities. The women dresses in that times contained a variety of cultures, bringing the quick development of the costumes and gorgeous light. The diversification, openness, containment and secularization in the Tang Dynasty women dresses had the similar spirit factors with the modern women dresses. Through the analysis of the aesthetic trend towards the modern women dress, comparing the aesthetic characters of the Tang Dynasty women dresses and the modern women dresses, analyzing the differences of the modern women dresses and the Tang Dynasty women dresses, to discuss how to combine the traditional costumes cultures and postmodernism and design the fashion clothes.
\end{abstract}

\section{The Trend of Diversification and Secularization on the Aesthetic Culture in the Tang Dynasty and Modern Times.}

The culture in the Tang Dynasty was prosperous and booming. After the founding, the rulers in the Tang Dynasty established the new ruling order; At the same time, they also encouraged the development of a variety of cultural genre, enlightened system and took political power to coordinate the relationship between the various culture, phase, and enabled the culture better service for the feudal rule in the Tang Dynasty. Finally, three major schools of Buddhism, Taoism and Confucianism culture landscape was formed in China. Under the affect of the kind of culture, people were suitable to the refined and popular tastes. As you know, the culture was used in the design of clothing through the spirit of secularism. But the secular aesthetic not stayed in vulgar culture of the desire level and sensory level, but spiritual solace which was created through the creation in the living through the hard work of the people. In the aesthetic culture of secular, People implemented the aim of the comfort heart, beyond himself, which was the purpose and awakening of traditional culture in 
"secular" cultural. In addition, the aesthetic spirit of secular, and diversified cultural also promoted the women costumes in the Tang Dynasty to be full of creation and many styles, becoming the most brilliant chapter in the history of China's costume.

After more than one thousand years, the people are living in a highly diversified living environment which is provided by the international style. They can not help but miss the living environment and lifestyle what they used to be. Just in this situation, the postmodern culture was appearing in this contradiction, and it again aroused people's pursuit for the diversified culture and spread around the world. The postmodernism brought great changes in the west, also brought great impact towards Chinese contemporary aesthetic culture.

On the one hand, the postmodernism held a denial attitude to the so-called objective truth in traditional art, which emphasized the perceptual aesthetic had broken the aesthetic to stay on the situation in the field of fine arts, putting art aesthetic into People's Daily life. Therefore, we could say that the culture of modern aesthetic began to have the characters of the secularization. On the other hand, the postmodernism was affecting the ideas of the artists, and great changes were experiencing towards the world. The artists gave up the pursuit to the object and the certainty. They thought that the art was uncertain; the art was open and was changing for all the times. Diversified there are evolving. Just as the famous philosopher German Wolfgang said: the postmodernism emphasized rather than attempting to kill or destroy differences, claiming the parallel paradigm, competing with each other, so it is a very complete diversity."

Due to the secular and diversified characteristics of the postmodernism, which also affected Chinese aesthetic culture. In China, modern women dresses changed from single style to the combination of many styles, which was the vivid manifestation of the affects towards Chinese aesthetic culture unconsciously. To sum up, we could get to know the close relationship between the Tang Dynasty and the modern aesthetic culture.

\section{The Difference Between the Women Dresses and the Modern Women Dress in the Characters of Aesthetic.}

Our country has a long history, and every dynasty had its distinctive features, but there was no any dynasty whose women clothing aesthetic culture development level could be compared with the Tang Dynasty. We compare the contemporary aesthetic culture with the Tang Dynasty, concluding that they were similar in many ways such as diversity, secularization, innovation and advocating the freedom of personality cultural spirit although after one thousand years. Therefore, we thought that the women dresses in today were a return in spirit.

The Aesthetic Popularity in the Tang Dynasty. Women dresses in the Tang Dynasty had the most gorgeous colors and various styles in the history of our country. Their main features were elegant and luxury, having many forms and types. (Figure 1) (Figure 2)

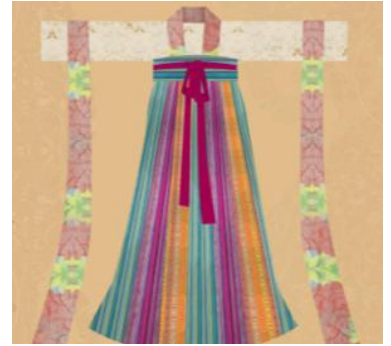

Figure 1.

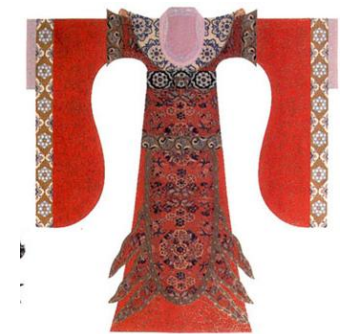

Figure 2.

\section{1) Flat Collar Dresses}

In the early Tang Dynasty, the women apparel continued the styles in the Sui dynasty. They were narrow in the upper part of the body, having two styles of cardigan and pullover. The lower part of the dresses was bind to with waist. The upper part of the dresses was low collar, and the neck and breast 
were obvious sometimes. In the middle of the Tang Dynasty, it was prosperous and blooming, a little fat women were more beautiful. So the dresses were loose. The sleeves were lengthened and widen. To wear the loose dresses had become the popularity in the Tang Dynasty. When women were dressing themselves, they put the waist dart in the place below the breast in the skirt waist, chest, upper body only wear strapless, outside with silk unlined upper garment, faint show skin. As you know, they were very fashion, and they wore breast dresses. They just wore upper silk garment outside, making the skin can be seen by the people.

\section{2 ) The Women Wore the Clothes of the Men}

According to the records of the old Tang book YUFU zhi, the popularity of the women wearing the men skirt in the Tang Dynasty happened. The painter Zhang Xuan in the Tang Dynasty was good at drawing the portrait of the ladies, whose works the portrait of the fanning lady showed the situation vividly. (Figure 3)

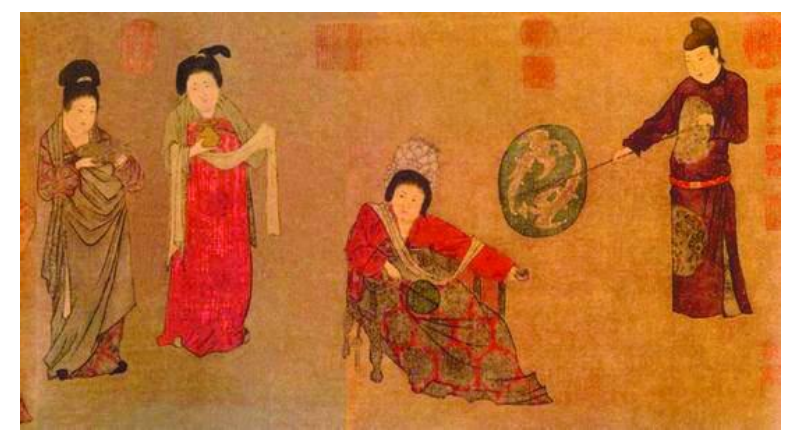

Figure 3. ( "Ladies" Waving

Fan)

\section{3) Hu's Dresses}

The Poet Yuan Zhen in the Tang dynasty once wrote the verse of $\mathrm{Hu}$ Yin, Hu ride and makeup, they were spreading quickly in the Tang Dynasty. Hu's clothing popularity was due to a variety of minority nationalities living together and cultural fusion. The Hu's dress had the major significance towards the dress in the Tang Dynasty and they had no utilitarian themselves. To some extend, they met with the needs for the new styles of the clothes in that time.

\section{4) Facial Cosmetics}

Women face makeup in the Tang dynasty had the characteristics of the ornate, natural and graceful, a variety of forms, could be said to be unprecedented. For example, the women put the facial powder on their faces, dye rouge lipstick, and then had the polish decoration in the yellow crescent on his forehead. The poet Lu Zhaolin had written that yellow spots on the fiber forehead to praise the beauty of the female face makeup. Women in the Tang Dynasty paid attention to the style of his eyebrows, they tent to pull out the really eyebrow, fully using black green to paint all kinds of popular eyebrow shape, and using silver, feather ornaments in brow ornament floral twink. The poet Wen Tingyun had written the poems of darken twinkle on the face to make up to describe the position and the color. (Figure 4) 


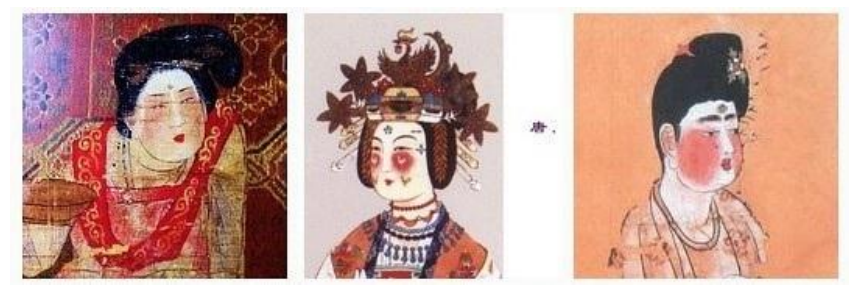

Figure 4.

\section{The Same Aspects of the Aesthetic Between the Women Dresses in the Tang Dynasty and Modern Times.}

\section{1) The Same Trend of the Dress Diversification}

Due to the historical conditions and the multiple cultural integration in the Tang Dynasty, formed a diversified social and cultural structure. This kind of diversified culture structure directly affected the social value orientation and aesthetic behavior of people at that time, which provided a wide range of cultural basis for designing all kinds of women dresses. It could be said that women clothing in the Tang Dynasty reflected the social openness.

The women in the Tang dynasty could wear the dress what they wanted according to their hobbies without breaking the moral codes of the imperial power taboo. From the masculine of men clothes and $\mathrm{Hu}$ clothes to the elegance of the feminine dress, from the creation of the flat collar dress to face makeup with richness and changes all reflected the cultural diversity and openness of the Tang Dynasty.

Contemporary women clothes had a lot of commons with the women dress in Tang Dynasty under the influence of the postmodernism. For example, the contemporary women clothes pursuit the aesthetic. In the design, there were no fixed styles and trend, but the comprehensive use of many elements. In the postmodernism view, pure eastern western costume or dress, was too single. Then, a variety of styles were considered when people were in the design of costume style, the contemporary women clothing began to have the characteristics of complexity, diversity and showed the rebellious people for a single social life, and appreciation of diverse clothing and tolerance.

\section{2 ) The Same Secularization of the Clothes}

If diversity represented the convergence of the change and the uniform, then the secularization represented a highly tolerant of new things for people. The contemporary women clothing not only has the characteristics of the diversity, but also secular characteristics. Under the influence of post modernism, the contemporary women dress had less implication of the religion relative to the Tang dynasty women clothing, but a little more freedom. Freedom and liberation was the essence of the contemporary women aesthetic culture content, also reflected the contemporary society for various forms of tolerance. Contemporary women clothing and women secular mental happen to coincide in the Tang Dynasty, just under this spirit of secularism promoted the continuous development of the contemporary women aesthetic.

The Difference of the Aesthetic Between the Modern Women Clothes and the Women Clothes in The Tang Dynasty. There were more than one thousand years between the modern clothes and the Tang Dynasty, therefore, there were some differences in the style of the aesthetic which came from the external force. The Tang Dynasty enlightened the policy, and the culture atmosphere was relatively free. The free cultural atmosphere promoted the development of the Tang Dynasty from the top to the bottom, which made the women clothes have the characteristics of diversity and freedom. On the other hand, the contemporary women clothing developed from the bottom to the top under the influence of the postmodernism. Such as hippie culture and punk culture was launched by folk, which was people's spontaneously change to the aesthetic fashion.

Secondly, the difference embodied in the clothing structure and the style. The women dresses in the Tang Dynasty had many forms and styles, and had the popularity for a long time, but there was 
fixation of the clothes match. However, the modern women dress melts many elements, and every suit could be departed and mashed up. (Figure 5) (Figure 6)
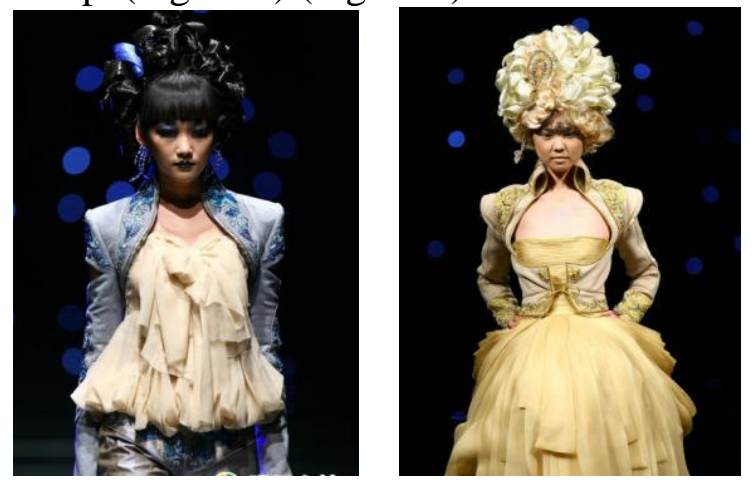

Figure 5. The Rose Studio, Guo Pei, Alta

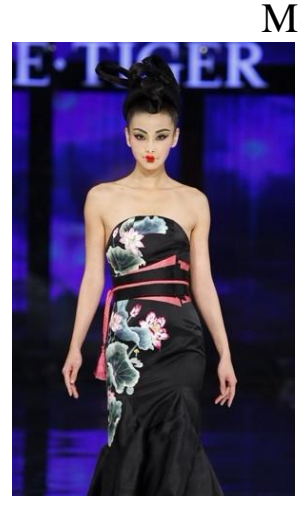

Moda in 2007

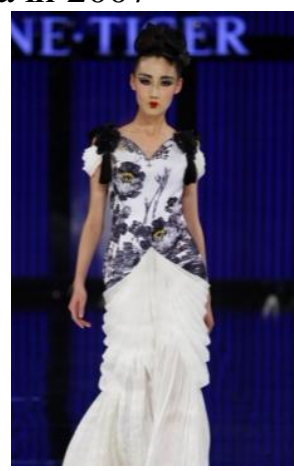

Figure 6. TIGER - NE Northeast Tiger 2012

Senior Custom Release

\section{CONCLUSION}

In the late $20^{\text {th }}$ century, the postmodernism influenced the western cultural thoughts. And spread in China for almost 30 years, which has great influence towards the women clothing design and creation. Although the spread of short history, of aesthetic culture in tang dynasty, However, there were great similarities between the women clothe in the Tang Dynasty and modern times in the goal of the women clothes design. As you know, every industry was in the situation of open and reform. When we are designing the dresses, we not only face the world and the future, but also inherit the traditional aesthetic culture of the costumes. Really reaching foreign used by China, ancient by today, to design the clothes in the attitude of absorbing anything and everything. In a word, when we are design the dress, we should base the deepen culture, melting the culture of the postmodernism, only in this way, to promote the development of the costumes culture.

\section{REFERENCES}

[1] Qi Yujie. The Application Research of the Elements of the Court Dress in the Prosperous Tang Dynasty [D]. Xi'an University, 2013

[2] Ke Lili. The Body Aesthetic and the Relation with the Clothes in the Tang Dynasty [D]. Beijing Institute of Fashion and Technology. 2015

[3] Chen Xia, the Research to the Modern Dresses Style [D]. Xi'an Art College, 2015 
[4] Qu Yang. The Analysis of the Fringe and the Application and Creation in the Fashion Design. [D]. Beijing Institute of Fashion Technology, 2013.

[5] Jin Jing. The Relationship Research between the Garment Culture Consciousness and the women dresses Forms [D]. China Art College, 2013.

[6] Wen Li. Research on Application of Paper-cut Stencil Art in the Women Dress Design. [D] Hunan Normal University, 3013.

[7] Liu Jiaojiao. The Style of Paper-cut Art in the Design of Modern Women Dress. [D] Jiangnan University, 2011

[8] Martin R H, Koda H. Haute couture [M]. Metropolitan Museum of Art, 1995.

[9] Chen Bin, the Style of Fashion Design [M]. The first version of september, 2007

[10] Liu Yuanfeng, the Clothes Design [M]. Beijing, Higher Education Press. 2005 